\title{
A sociedade sambaquieira vista através de sexo e gênero
}

\author{
Maria Dulce Gaspar* \\ Maria Luiza Heilborn** \\ Eliana Escorcio***
}

GASPAR, M, D., HEILBORN, M. L., ESCORCIO, E. A sociedade sambaquieira vista através de sexo e gênero. R. Museu Arq. Etn., São Paulo, n. 21, p. 17-30, 2011.

Resumo: A pesquisa em sambaquis é um tema fundador da arqueologia brasileira e existe uma extensa e variada produção científica sobre esse tipo de sítio arqueológico. Entretanto, a grande maioria dos estudos sobre a sociedade que colonizou o litoral preocupa-se em enquadrá-las em modelos de classificação que não contemplam em suas análises os diferentes segmentos sociais que as integram. $O$ estudo sobre gênero é um caminho profícuo para identificar e caracterizar segmentos sociais que compartilham o mesmo espaço e ideologia. Tendo por pano de fundo a trajetória do conceito de gênero nas ciências sociais e seus desdobramentos para a arqueologia de sambaquis, o artigo analisa elementos dos contextos funerários desses sítios identificando a presença de construções simbólicas de extrema variabilidade que apontam para aspectos da vida social dos pescadores-coletores do litoral do estado do Rio de Janeiro.

Palavras-chave: Sambaqui - Pescadores-Coletores - Gênero - Organização Social.

\section{Introdução}

$\mathrm{O}$ estudo dos sambaquis confunde-se com a própria formação do campo de Arqueologia no Brasil. No início, o debate consistia em estabelecer se estes sítios eram formações naturais ou artificiais e, após a década de 1940, prevalecem questões norteadas pelos

(*) Museu Nacional da Universidade Federal Rio de Janeiro.<madugaspar@terra.com.br>

$\left.{ }^{* *}\right)$ Universidade Estadual do Rio de Janeiro. <marialuiza. heilborn@gmail.com>

$\left.{ }^{(* *}\right)$ Museu Nacional da Universidade Federal Rio de Janeiro. Mestre em arqueologia MNRJ/UFRJ. <e.escorcio@terra.com.br> princípios do evolucionismo social e destaca-se a preocupação em estabelecer se os pescadores-coletores que colonizaram o litoral brasileiro, por volta de sete mil anos atrás, estavam organizados enquanto bando, macro-bando ou se era uma sociedade complexa ou em processo de complexificação (Uchôa 1973; Machado 1984; Lima e Lopez Mazz 1999; DeBlasis et al. 1998). A arqueologia brasileira tem estudado a sociedade sambaquieira a partir da caracterização de sua organização social sem identificar segmentos sociais e estabelecer especificidades de seus diferentes componentes no jogo político. São poucos os estudos que se preocuparam em entender a trama social, Gaspar (1991), Kneip (2004) e DeBlasis et al. (2007) dedicaram-se a identificar 
indícios de hierarquia entre assentamentos que integram um mesmo conjunto de sítios, Lima e Lopez Mazz (1999) apontaram a existência de diferentes segmentos sociais compostos por líderes e não-líderes, Gaspar (apud DeBlasis et al. 2004) sugeriu a existência de grupos de afinidade a partir da distribuição espacial de esqueletos e Okumura e Eggers (2011) investigaram as especificidades biológicas dos indivíduos sepultados em uma mesma área funerária. Estudo sobre gênero é, também, um caminho profícuo para entender o funcionamento da sociedade sambaquieira, ele permite identificar segmentos sociais que compartilhavam o mesmo território, ideologia e participavam do jogo político inerente à vida social.

Os estudos sobre gênero, no que se refere aos sambaquieiros, bem como no que se refere à arqueologia brasileira como um todo, ainda têm um longo caminho a percorrer (Lima 2003: 136). A tese de Sene (2007), em contexto de grupos horticultores do interior de Minas Gerais, busca entender, a partir do estudo de rituais funerários e remanescentes ósseos humanos, as relações sociais e simbólicas sob o ponto de vista das elaborações de gênero. Rodrigues-Carvalho, em sua tese de doutorado (Rodrigues-Carvalho 2004), analisa marcas de estresse ocupacional e procura identificar diferenças com relação aos sexos no contexto de grupos sambaquieiros do litoral do estado Rio de Janeiro, explorando novas linhas de investigação para o entendimento das relações de gênero enquanto parte de um conjunto mais amplo de relações sociais. O estudo de Escorcio e Gaspar (2005) é uma contribuição neste sentido. As autoras analisaram os acompanhamentos funerários presentes no sítio Corondó em busca de indicadores de diferenciação social e de gênero e a análise empreendida confirmou a presença de indivíduos com status superior à maioria do grupo em questão, de elementos que diferenciam adultos e jovens, e de elementos associados aos gêneros, entre os quais um aumento do prestígio feminino ao longo do tempo. Em outro estudo, as mesmas autoras ampliaram suas reflexões sobre gênero para o conjunto das sociedades sambaquieiras que ocuparam o litoral do estado Rio de Janeiro, para as quais existe bibliografia descritiva disponível (Escorcio e Gaspar 2010). Parte do presente trabalho toma por base dados e considerações levantados nesse estudo.

Por considerar que gênero é também um aspecto ordenador da sociedade sambaquieira, é importante que se retome aqui a história de formação desse campo de saber nas ciências sociais. Este artigo discute a universalidade da distinção sexo/gênero e leva em consideração que os princípios que norteiam as sociedades nativas sul-americanas, em particular a sociedade sambaquieira, são distintos das sociedades ocidentais em que foi cunhado o conceito de gênero.

Com vistas a buscar especificidades do modo de vida dos pescadores-coletores foram levantados os dados de sepultamento, em especial dos acompanhamentos funerários em associação a esqueletos identificados por sexo e idade, de dezoito sítios arqueológicos localizados no estado do Rio de Janeiro, entre a baía de Ilha Grande e Macaé, a partir de uma releitura das arqueografias produzidas por Kneip (1977, 1987, 2001), Kneip e Machado (1993), Kneip, Machado e Crancio (1995), Livro de Tombo da Ilha da Boa Vista I (No 2118 a 2131), Machado (1984), Machado, Pons e Silva (1989b), Machado e Sene (2001), Lima (1991), Bezerra (1995), Barbosa (2007), Tenório (2003).

\section{Sexo e gênero}

Desde a década de 1970 as ciências humanas, as sociais em particular, foram marcadas pela progressiva incorporação do conceito de gênero. A distinção entre sexo e gênero constitui-se numa ferramenta conceitual e política, pois ela representou um forte argumento nas lutas políticas em torno dos direitos das mulheres. Nessa diferenciação, o primeiro termo, sexo, remete à natureza e, de maneira mais específica, à biologia e o segundo, gênero, às construções culturais das características consideradas femininas e masculinas (Scott 1990). Essas construções são percebidas como aspectos que mantêm relação com a biologia, mas não derivam dela e variam (em diferentes contextos) (Shapiro 1981). Ao colocar em evidência o caráter arbitrário 
das noções de masculinidade e feminilidade, a distinção entre sexo e gênero permitiu que pesquisadoras e também militantes feministas salientassem a natureza eminentemente social da subordinação das mulheres e, portanto, para sua possível alteração (Franchetto, Cavalcanti e Heilborn 1981; Mathieu 1991).

O conhecimento antropológico foi central na reunião de elementos substantivos para formular essa distinção. Contudo, como é natural no ofício científico, posteriormente essa distinção tão difundida - e incorporada ao senso comum hoje em dia - foi também problematizada. Em tempos atuais, o conceito de gênero passou a ser alvo de questionamento por ter suas raizes na tradição de pensamento que sustenta a diferenciação universal entre natureza e cultura (Strathern 1988).

\section{Histórico do conceito}

\section{A distinção sexo/gênero integra a história} das teorias sociais sobre a "diferença sexual". Já entre os chamados fundadores do pensamento sociológico é possível rastrear a sugestão da idéia de diferença sexual como princípio universal de diferenciação e classificação (Durkheim e Mauss (1971) [1903]. Assim, firma-se uma linha argumentativa de que a diferença sexual é produto da cultura e não de um substrato natural ou essência que informaria a modelação dos então chamados papéis sexuais.

Os papeis sexuais constituem a aplicação da teoria dos papéis sociais - que focaliza os fatores que influenciam o comportamento humano - na esfera da divisão de trabalho material e moral entre os sexos. Indivíduos nascidos e classificados como homens e mulheres seriam socializados a agir, pensar e sentir segundo roteiros culturalmente construídos em posições vinculadas ao sexo anátomo-biológico. As análises comparativas desenvolvidas segundo a teoria dos papéis mostraram que a crença sobre a existência do temperamento inato ligado ao sexo não é universal. A evidência oferecida é o fato de que embora diversas sociedades institucionalizem de alguma maneira os papéis de homens e mulheres, não o fazem necessariamente em termos do contraste entre as personalidades dos dois sexos (Mead 1969).
As abordagens que trabalham com a perspectiva dos papéis mostram a construção cultural dos mesmos e esposam certa idéia do social: elas tendem a conceber as relações entre os sexos a partir de pressupostos de costume e estabilidade social e, em geral, tendem a descartar a incorporação de mudança nesse arranjo social. Uma reflexão crítica dessa perspectiva pode ser observada no conceito de "sistema de sexo e gênero”, formulado por Gayle Rubin (Rubin 1975), que postula que a assimetria entre homens e mulheres presentes em múltiplas sociedades deveria ser debitada às formas de organização social do sexo e da reprodução. Interpelando Lévi- Strauss (1976) na teoria sobre a circulação de mulheres, Rubin assevera que a desigualdade de distribuição de poder está na raiz da apropriação pelos homens da capacidade reprodutiva do sexo feminino. Essas idéias são centrais no desenvolvimento da antropologia dedicada ao gênero nas décadas de 1970 e 1980 (Harris e Young 1979; Reiter 1975).

No marco de abordagens que consideram a subordinação feminina um aspecto universal da organização social, o conceito de gênero foi amplamente utilizado para aludir à construção social das diferenças entre homens e mulheres. $\mathrm{O}$ foco de interesse era compreender as maneiras como essas construções se relacionavam $\mathrm{com}$ as práticas sociais situando às mulheres em posições de desigualdade. Algumas antropólogas definiram gênero como uma forma de desigualdade social (Ortner e Whitehead 1981; Collier e Yanagisako 1987) e consideraram o estudo do gênero como o estudo de relações assimétricas de poder e oportunidades. Enquanto algumas linhas teóricas persistiram nessas formulações (Tabet 1998), outras contestaram os fundamentos desse estilo de análise.

A crítica parte da negação da universalidade da dominação masculina (Bourdieu, 1992). O principio da supremacia masculina presente em todas as culturas garantindo aos homens mais prestígio do que às mulheres. Segundo tal modelo, as mulheres seriam controladas em função de suas capacidades reprodutivas (Héritier 1989), e/ou inferiorizadas por tais capacidades, que as colocariam do lado da natureza, das emoções, do doméstico, do privado (Rapport e 
Overing 2000). Essas idéias foram consideradas parte de um referencial teórico "ocidental", historicamente datado, embasando os aparatos conceituais mediante os quais se pretendia analisar todas as outras sociedades, obscurecendo suas especificidades.

Essa postura crítica se insere em uma linha de questionamentos à distinção entre sexo e gênero que remete aos fundamentos da construção do conhecimento ocidental. As mencionadas abordagens sustentam-se em pilar epistemológico problemático: a própria distinção sexo/gênero. Pois a categoria sexo enquanto realidade física não é objeto de problematização histórico-cultural (Laqueur 2001). No binômio sexo-gênero, o primeiro termo aparece como objeto de conhecimento da biologia, numa particular tradição ocidental na qual o corpo é página em branco a ser formatada por marcas, inclusive aquelas produzidas pelo discurso biológico. Na tradição ocidental cartesiana o objeto de conhecimento é matéria para o ato do sujeito que analisa e a "natureza” é tão somente matéria prima para a cultura (Haraway 1991).

Argumenta-se que a noção de sexo, ou da natureza biológica de homens e mulheres, é uma construção social (Moore 1994; Oudshoorn 1994). Isto é, o que é reconhecido como corpo sexuado, fisicamente diferente, não é algo que, levando em conta as idéias de outras sociedades sobre a realidade física, possa ser considerado um dado universal. Assim, tanto a distinção entre sexo e gênero como as idéias de poder a ela associadas estendem a outras sociedades concepções sobre as relações entre homens e mulheres presentes nas sociedades "ocidentais" e devedoras do pressuposto da dicotomia entre sujeito e objeto. Esta dicotomia, por sua vez, deriva de noções de poder (dominação/submissão) vinculadas à noção de "propriedade" e a uma visão do mundo "natural" como algo fixo sobre o qual se atua, no plano da cultura (Strathern 1980; Jordanova 1980). Esta nova perspectiva rejeita a universalidade da distinção sexo/gênero para o conjunto das diversas culturas existentes ou desaparecidas.

No que concerne às sociedades ameríndias, o debate travado entre os defensores da idéia de que há hierarquia de gênero nessas sociedades e os adeptos da teoria da complementaridade simétrica entre os gêneros possui bastante vigor. Importa para os fins deste artigo os signos utilizados para demarcar os sexos e os gêneros nessas sociedades e que vêm acompanhados de utensílios da vida cotidiana. O estudo de Silva (s/d) sobre os Enawene-Nawe, grupo Aruak da Amazônia meridional assinala que a passagem à vida adulta é socialmente marcada por emblemas da sexualidade e da capacidade reprodutiva de ambos os sexos: o estojo peniano e as tatuagens no ventre e nos seios, signos de valor na economia simbólica desse grupo. A condição de adulto é atingida por rituais que não só apresentam adornos corporais específicos à maturidade sexual e social como também a substituição dos utensílios diários por novos, a saber, para a moça novas panelas, e para o menino-rapaz novos arco e flechas.

Estabelecer especificidades referentes a gênero é uma via para identificar segmentos sociais em culturas pré-coloniais, estabelecer e entender articulações sociais. Para tanto, considera-se que a distinção tenha manifestação material quer no próprio corpo em decorrência de atividades físicas específicas e/ou em adereços. Tratando-se de sociedades extintas consideram-se, também, objetos e arranjos tanto do próprio corpo e dos acompanhamentos dispostos pelos orquestradores do ritual funerário. Parte-se do princípio que há uma relação de continuidade entre atributos vivenciados e representados na morte.

\section{Sambaquis, acompanhamentos e gênero}

Nos contextos funerários de sambaquis do litoral do estado do Rio de Janeiro podem ser observados componentes de sua cultura material como pontas ósseas de variados tipos, artefatos líticos, conchas, adornos de diferentes materiais e corante na forma de concreções e sedimentos. A reflexão sobre a forma como se distribuem esses elementos em contexto de enterramento proposta neste artigo buscou perceber a existência, ou não, de uma associação clara entre um determinado artefato e o sexo biológico da pessoa ali enterrada como base para inferências sobre confi- 
gurações de gênero nas sociedades sambaquieiras. Esta é uma tarefa cercada de dificuldades, seja pela escassez de dados para uma contextualização mais ampla, seja pelo fato de os sambaquieiros há muito se encontrarem desaparecidos quando do início da ocupação européia não havendo, portanto, relatos diretos ou indiretos sobre esses grupos sociais. Em acréscimo, cabe ressaltar ainda que estudos etnográficos não se ocupam com frequência dos acompanhamentos funerários e sua simbologia nos relatos de sociedades ágrafas caçadoras, ou pescadoras- coletoras, deixando de fornecer essenciais subsídios para uma reflexão comparativa.

Evidências mortuárias são valiosas fontes de informação sobre configurações de gênero quando obtidas sob condições ideais tais como remanescentes esqueléticos bem preservados e analisados por diferentes especialistas, grande número de enterramentos escavados sistematicamente, evidências iconográficas entre outros aspectos (Arnold 2006: 140, 146). Os dados de que dispomos para os construtores de sambaquis estão longe de preencher esses requisitos, as descrições existentes são de extrema variabilidade quanto ao conteúdo, profundidade e extensão. Por outro lado, o que está potencialmente representado em um contexto funerário pode corresponder ou não à prática real da ideologia de gênero daquela sociedade, ao mesmo tempo em que não se limita a expressar o aspecto de feminilidade ou masculinidade do enterrado, mas também o universo simbólico relacionado à transição do mundo dos vivos para o mundo dos mortos (Arnold 2006: 137).

Ao tentar propor inferências sobre construção de gênero entre os sambaquieiros levamos em consideração as descrições de enterramento encontradas na bibliografia, tendo em mente as restrições referidas anteriormente. Do conjun- to das arqueografias disponíveis, e que foram objeto de análise na dissertação de mestrado de Escorcio (2008), consideramos neste estudo apenas os sítios cujas escavações revelaram um número mais significativo de sepultamentos e de esqueletos com sexo identificado e, portanto, potencialmente mais capazes de refletir, no âmbito da distribuição dos acompanhamentos, uma ação social que possa ter concorrido para originar o registro arqueológico. Incluímos, também, alguns sítios com menor número relativo de indivíduos, mas que apresentaram em seus contextos elementos pertinentes ao desenvolvimento desta análise.

Os sítios considerados, e as respectivas obras de referência, com o número de indivíduos do sexo feminino e masculino identificados encontram-se na Tabela 1 .

Tabela 1

No de indivíduos identificados por sexo

\begin{tabular}{lrrl}
\hline \hline Corondó & 32 & 25 & Machado 1984 \\
Beirada & 15 & 13 & Kneip e Machado 1993 \\
Moa & 12 & 13 & Kneip e Machado 1993 \\
Zé Espinho & 7 & 13 & Kneip 1987 \\
Ilhote do Leste & 2 & 12 & Tenório 2003 \\
Ilha da Boa Vista I & 5 & 9 & Livro de Tombo \\
Algodão (inferior) & 5 & 4 & Lima 1991 \\
Tarioba & 3 & 6 & Machado e Sene 2001 \\
Forte & 1 & 4 & Kneip 1977 \\
Itaúnas & 1 & 2 & Barbosa 2007 \\
\hline
\end{tabular}

Como diretrizes norteadoras da análise empreendida:

- A suposição de que uma cultura material simples, em termos relativos, não é sinônimo de sociedade simples, no sentido das suas elaborações simbólicas (Fausto 2000: 67);

- A consideração de que, mesmo quando a igualdade social possa se constituir em um forte aspecto de uma dada sociedade, ela nunca se dá em termos 
absolutos (Flannagan 1989: 247-248), ocorrendo, na prática, contextos de igualdade e contextos de desigualdade ou assimetria, frutos, nos dois casos, de elaborações sociais;

-A constatação de que a caça é valorizada simbolicamente no continente americano, seja entre os grandes caçadores do Alasca e do Canadá, seja entre sociedades de horticultores da floresta tropical (Viveiros de Castro 2002: 357) Pressupõe-se que a caça, embora tenha sido apenas um componente complementar na dieta dos sambaquieiros, era também uma atividade valorizada. É observada em contextos funerários a presença de pontas de projéteis e adornos de dentes de animais, tanto aquáticos quanto terrestres. Há menção, também, à presença de porções de caça como parte de festim fúnebre (Klokler 2008).

\section{Corante}

O corante é o componente mais comum nos cenários de enterramento de sociedades pretéritas e seu uso é muito antigo (Mithen 1996: 36). Há sítios de sambaquieiros em que ele está presente de (1) forma marcante, (2) sítios onde ele está totalmente ausente, e (3) situações intermediárias entre esses dois extremos. Em dois sítios às margens da lagoa de Araruama, na Região dos Lagos, a distribuição do corante ocorre da seguinte forma: no Beirada, com quinze mulheres e treze homens, oito delas têm o corante, enquanto ele ocorre para seis homens; no Moa, de doze mulheres, nove levam o corante, de treze homens, nove o possuem em seu enterramento. Para o Corondó, situado na região de Arraial do Cabo, cuja escavação revelou trinta e duas mulheres e vinte e cinco homens, são vinte e duas as mulheres que apresentam o corante, os homens totalizam dezenove. No Zé Espinho, um sambaqui localizado na área da baía de Sepetiba, com sete mulheres e treze homens sepultados, nenhum deles possui o corante.

Há uma discussão entre os arqueólogos quanto à função do corante em um enterramento sambaquieiro, considerando-se que não necessariamente teria um caráter simbólico podendo tratar-se de uma medida prática para afastar odores, por exemplo. Pode-se considerar, também, que se trata de um hábito correlacionado com o tratamento dado aos corpos dos vivos, a pintura corporal, tão frequente entre os nativos sul americanos. Seja qual for sua finalidade, o que se pode observar na distribuição do corante nos enterramentos dos sítios citados é que homens e mulheres em quantidades significativas o recebiam, assim como homens e mulheres deixavam de recebê-lo.

\section{Pontas ósseas e adornos de dentes de animais}

As pontas ósseas consideradas neste estudo são aquelas descritas nos trabalhos arqueológicos como possuindo função de ponta de projétil, ou seja, aquelas potencialmente associáveis às atividades de pesca e caça.

As considerações sobre esses artefatos remetem a um modelo teórico em voga nas décadas de 1960/70 que atribuía a evolução humana ao desenvolvimento da caça, o modelo "homem, o caçador" (Lee e Devore 1968) e seu modelo complementar, "mulher a coletora" (Dahlberg 1981). Ambos foram amplamente criticados no artigo fundador da arqueologia de gênero nos Estados Unidos, de Conkey e Spector (1984), por seu pressuposto de divisão rígida de tarefas entre homens e mulheres.

Um estudo etnoarqueológico empreendido por Brumbach e Jarvenpa (1997) entre os Chipewyan, que vivem na região sub-ártica do Canadá, alimentando-se predominantemente da caça, nos mostra que homens e mulheres organizados em grupos, sob diversas formas de combinação, seja de várias famílias reunidas, mulher e marido, pai e filha etc participam da caça ao alce e ao caribu. Os homens realizam a matança propriamente dita, mas as parcerias entre homens e mulheres facilitam o fluxo das diversas etapas envolvidas no ato de "caçar", que vai muito além do momento do abate, como o deslocamento, rastreamento, carneamento, processamento e a distribuição da carne.

Há também o exemplo etnográfico das mulheres caçadoras Agta, das Filipinas, que rompe com os cânones estabelecidos outrora para os 
papéis sexuais. Essas mulheres são responsáveis elas próprias pelo abate de animais de certo porte, como porcos selvagens e veados, caçados por elas com arco e flecha (Estioko-Griffin e Griffin 1981: 121-129).

Com relação aos sítios arqueológicos em foco neste estudo, no sambaqui Zé Espinho foram relatados uma mulher e dois homens com pontas em seus contextos funerários. No Corondó, cinco mulheres e três homens apresentam este artefato em seus sepultamentos. Para o Beirada e o Moa não foi relatada a presença de pontas em sepultamentos, nos estudos revisados.

Os adornos de dentes de animais são artefatos relacionados ao ato de caçar ou pescar, pela sua forma de obtenção. No sítio Corondó três mulheres e três homens têm adornos de dentes de animais. No Beirada ele ocorre em um único contexto funerário, o de uma mulher. Para um outro sítio, o Ilha da Boa Vista I, também é relatada a presença de adorno de dente de animal no sepultamento de uma mulher, assim como no sítio Algodão uma mulher também tem adorno de dentes de animais.

A não ser que se opte por uma interpretação baseada na essencialização de papéis de gênero ocidentais contemporâneos, a qual induziria à aplicação, por vezes inconsciente, do “duplo padrão" (Nelson 2004: 106) - artefatos "típicos" do universo masculino encontrados em enterramento masculino, correlação direta, os mesmos artefatos quando observados em enterramentos femininos, correlação direta descartada - semelhante registro arqueológico, como o descrito acima, não enseja motivos para se excluir por princípio a correlação de mulheres sambaquieiras às atividades de pesca ou caça, e/ou à simbologia representada pelas pontas de projétil e pelos adornos de dentes animais. A forma como surgem nos contextos de enterramento relatados se coadunaria melhor como expressão de papéis sociais não rígidos, e/ou com a existência de parcerias entre os gêneros. $\mathrm{O}$ animal de onde se retirava esses dentes para adornos também indica esta direção, visto que parece não haver associação específica de nenhum animal a nenhum dos sexos, conforme a Tabela 2.
Tabela 2

Indivíduos com adornos de dentes de animais

\begin{tabular}{lcl}
\hline \multicolumn{1}{c}{ Sítio } & Sexo & \multicolumn{1}{c}{ Identificação } \\
\hline \hline Corondó & F & cachorro do mato \\
& F & felino \\
& F & seláquio \\
& M & felino \\
& M & cachorro do mato \\
& M & não identificado \\
& M & felino \\
Ilhote do Leste & M & seláquio, primata \\
& M & seláquio \\
Beirada & F & primata \\
Ilha da Boa Vista I & F & não identificado \\
Algodão & F & mamífero \\
\hline
\end{tabular}

Legenda: $\mathrm{F}=$ feminino, $\mathrm{M}=$ masculino

Do ponto de vista de um universo simbólico mais amplo, a presença de adornos de dentes de animais sugeriria também a interação humano/ animal segundo o perspectivismo ameríndio proposto por Viveiros de Castro (2002). ${ }^{1}$ Abordagem que também, poderia dar conta da presença de adornos confeccionados com dentes humanos e característicos de alguns sambaquis como o Corondó em que é descrita a presença deste tipo de adorno para uma mulher e para um segundo indivíduo de sexo não identificado (Machado 1984).

\section{Líticos diversos}

Nesta categoria consideramos os artefatos líticos descritos como lascas, polidores, raspadores, percutores, almofarizes e quebra-coquinhos. No geral, o que se observa são homens e mulheres com esses tipos de artefatos em seus sepultamentos, não se definindo qualquer tendência de atribuição para nenhum dos sexos.

(1) No universo simbólico do perspectivismo ameríndio, animais se vêem como humanos, o que difere homens e animais é seu aspecto exterior, sua aparência física. 
Lâminas de machado

As lâminas de machado ("polidas" ou "lascadas e polidas") ocorreram em sepultamentos do Ilhote do Leste e do Zé Espinho, ambos na área de Sepetiba, no Moa e no Forte, ambos na Região dos Lagos. Consideraremos apenas os três últimos sítios, visto que no Ilhote do Leste parece ocorrer uma subrepresentação das mulheres na amostra.

No Zé Espinho um único homem tem lâmina de machado em seu sepultamento, o mesmo ocorrendo no Forte. No Moa, são observados três homens e duas mulheres com lâminas. Analisando as idades atribuídas a esses indivíduos do Moa, temos dois homens na faixa de 30/35 anos com duas lâminas cada um deles e um terceiro com uma única lâmina, estando este na faixa etária descrita como acima de 25 anos. Uma das mulheres tem entre 40 e 50 anos de idade, a outra entre 30 e 35 . Ambas possuem uma única lâmina de machado cada uma em seus sepultamentos.

Considerando a quantidade como um componente das construções simbólicas, uma única lâmina para as mulheres do Moa, sendo uma dessas mulheres bem idosa para os padrões em sambaquis, as colocaria em um patamar simbólico semelhante ao do homem de menor idade relativa que tem também apenas uma lâmina. Projetando sobre este quadro um viés hierárqui$\mathrm{co}$, as mulheres estariam em um patamar inferior ao dos homens de idade aproximada às suas. Entretanto, refletindo em uma outra direção, é possível pensar esse perfil do registro arqueológico em termos de uma aproximação dos universos masculino e feminino na idade mais avançada. Algo da natureza do que ocorre na sociedade Kayapó do Brasil Central, conforme interpretado por Vanessa Lea, em que "a idade tende a dissolver a distinção entre os sexos” (Lea 1994: 99-100).

\section{Seixos polidos}

Os seixos polidos, com ou sem corante, parecem imbuídos de uma função simbólica especial, seja por sua associação ao corante, seja por sua forma de disposição nos enterramentos conforme sugerem as descrições.
Considerando apenas os seixos pintados, eles ocorrem em sepultamentos em quatro sítios, Zé Espinho, Moa, Corondó e Tarioba. No Corondó, o seixo pintado apresenta uma distribuição que se constitui em um dos poucos "quase" padrões em contexto de sambaqui. $\mathrm{O}$ seixo pintado é quase exclusivo de mulheres ou de grupos de mulheres com crianças. Este quase padrão observado no Corondó é um dos raríssimos traços de predomínio em matéria de acompanhamento funerário, pelo que nos foi possível depreender das descrições revistas. Um outro "quase" padrão, também marcante no Corondó, diz respeito aos adornos infantis, em que o número de peças dos adornos das crianças, em especial das bem pequenas, é frequentemente maior do que o número relativo de peças do adorno de um adulto.

\section{Um sepultamento sambaquieiro}

A ausência de padrões recorrentes e rígidos nas atribuições de acompanhamento funerário em contexto sambaquieiro talvez seja o fato maior a se destacar. $\mathrm{O}$ cenário de enterramento que descrevemos a seguir é bastante representativo desta asserção. Trata-se de um sepultamento triplo, dois homens e uma mulher, encontrado no sítio Itaúnas, descrito por Márcia Barbosa (Barbosa 2007: 164), do qual apresentamos um resumo descritivo: A área em redor do sepultamento encontrava-se delimitada por estacas que são indicadores da existência de uma estrutura leve. Os três indivíduos, dispostos em uma mesma orientação, encontravam-se cobertos por sedimento arenoso avermelhado que impregnou os ossos, objetos e fauna que compunham a parafernália ritual. A mulher à esquerda no conjunto, com cerca de 30 anos, estava em decúbito dorsal com a face para cima, membros inferiores e superiores estendidos. Uma valva da concha Lucina pectnata encontrava-se sobre cada uma das órbitas de sua face. Havia uma ponta óssea sobre seu fêmur direito. Ao centro, um homem de cerca de 20 anos, membros também estendidos e em decúbito dorsal, tinha sua face voltada para o Leste. Suas órbitas encontravam-se igualmente cobertas cada uma delas por uma 
Lucina pectinata, um seixo polido posicionava-se entre seus membros inferiores, havia um outro seixo próximo à mão direita. $\mathrm{O}$ terceiro indivíduo, um homem de mais de 20 anos, à direita no conjunto, encontrava-se em decúbito ventral com a face para Oeste e os membros estendidos. Ele possuía, ainda, um adorno de placa óssea, além de duas pontas junto às costelas, em seu lado direito.

Diferenças de status entre esses indivíduos poderiam estar em jogo aqui, conforme sugeriu Barbosa (2007: 164). Entretanto, consideramos que essas diferenças de status, expressas pela distribuição dos acompanhamentos e outros aspectos do sepultamento, não corresponderiam a uma gradação absoluta em termos de inferioridade e superioridade. Elas expressariam elaborações simbólicas indicativas de níveis variados de igualdade e desigualdade, refletindo diferentes papéis que um mesmo indivíduo poderia encarnar dentro de um grupo social. Essa interpretação encontra respaldo na variabilidade recorrentemente observada em contexto de sambaquis, que procuramos destacar, variabilidade esta que parece se coadunar mais com a idéia de uma plasticidade social do que com a pressuposição de papéis rígidos para os gêneros no contexto das sociedades sambaquieiras.

\section{Conclusão}

A busca por padrões de sepultamentos ${ }^{2}$ foi e é um tema recorrente em Arqueologia, mas especialmente a que está voltada para o entendimento da sociedade sambaquieira. A grande quantidade de esqueletos humanos recuperada em escavações torna atraente esse tipo de abordagem muito embora as análises não tenham identificado padrões que dessem conta dos rituais funerários que integram sambaquis em sua totalidade ou que integram um determinado agrupamento de sítios. Semelhanças e diferenças parecem se destacar de maneira alternada

(2) Essa busca abrange, também, padrões de assentamentos ou na maneira de confeccionar artefatos, a qual está expressa em inúmeras tipologias existentes. em cada análise sugerindo que, ao invés de padrões rígidos relacionados com o sepultamento, articulavam-se condutas padronizadas com tratamentos específicos de cada corpo ou conjunto de corpos.

Um jogo em que aspectos estruturais e conjunturais se complementavam. Por um lado, era uma regra sepultar corpos nas proximidades de mar, lagoa ou rio e em locais construídos e que se caracterizam por se destacar na paisagem em decorrência do acúmulo de material faunístico. $\mathrm{O}$ fogo, a proximidade de outros corpos, também eram elementos constantes e pesquisas recentes sugerem que a oferenda de alimento parece ter sido um hábito. Por outro lado, há esqueletos fletidos, hiper-fletidos, estendidos, com membros superiores e inferiores em posições distintas, orientação dos corpos e cabeça em direção variada. Alguns estão cobertos de conchas, outros são precedidos por grandes blocos de pedra e os acompanhamentos funerários são variados como mostra o nosso estudo. Plasticidade e ausência de papéis gênero rigidamente definidos parecem ser características marcantes da sociedade sambaquieira. É bem provável que o estudo de gênero aqui empreendido aponte para aspectos estruturais do modo de vida dos pescadores-coletores que ocuparam a faixa litorânea entre a baía de Ilha Grande e Macaé, já que não há, também, indícios de um segmento social que se destaque entre os demais membros da sociedade e que tivesse uma posição hierárquica diferenciada e estabelecida. Apoiando-nos nas reflexões de Klokler (2008) sobre as festividades mortuárias, tomadas como cruciais para coesão e solidariedade social, há apenas indícios de desigualdade social incipiente.

É preciso lembrar que não se fala aqui de ausência de liderança, aspecto pertinente a todas sociedades, mas sim de ausência de hierarquia instituída, aspecto característico de sociedades complexas. Arnold (1996) destaca, entre inúmeros aspectos sociais mencionados por diferentes estudiosos, a presença de padrões de organização social supra-parentesco e de mecanismos regulares de controle de forca de trabalho para a caracterização de sociedades complexas. Não há evidências destes aspectos sociais no modo de vida dos sambaquieiros que ocuparam 
o litoral do Rio de Janeiro. No que se refere a diferenciação, nota-se um corte etário em que crianças se diferenciam dos demais membros e, como já havia sido mencionado por Escorcio e Gaspar (2005), indivíduos com status superior aos demais. Com relação ao corte etário, trata-se de um "quase" padrão em que crianças são ornadas com um número de peças superior as dos adultos. Colares de conchas diminutas por vezes adornam o dorso dos pequenos e apontam para o tratamento diferenciado para membros desse segmento social, não para todos, é de se destacar.

Analisando outros aspectos já estabelecidos para a sociedade sambaquieira é possível desenhar alguns princípios sociais ordenadores desse modo de vida. Estudos voltados para a caracterização da área de captação de recursos dos sambaquieiros que ocuparam a região dos Lagos apontam para existência de comportamento cooperativo entre os construtores de sambaquis que integram um conjunto de sítios e a análise de artefatos sugere ampla circulação de pessoas através da linha de costa. Cooperação que é reforçada pela exploração de grandes corpos de água onde os recursos são abundantes e renováveis e, portanto, passíveis de exploração conjunta (Gaspar 1991). Estudos sobre pescadores tradicionais da região Sul (Gaspar et al., no prelo) sugerem, também, que a atividade pesqueira tende a propiciar o comportamento cooperativo. No domínio simbólico dos sambaquieiros, destaca-se o cuidado com os corpos e é bem possível que na região Sudeste, da mesma maneira como ocorre na região Sul, cooperação e circulação tenham sido ingredientes fundamentais de seu ritual funerário (Gaspar 2004; Klokler 2010). Ausência de papéis de gênero muito bem definidos, como parece indicar a variabilidade na atribuição dos acompanhamentos funerários, e ausência de hierarquia estabelecida desenham uma sociedade bastante plástica em que aspectos conjunturais da vida social norteavam a relação entre os diferentes segmentos sociais.

GASPAR, M, D., HEILBORN, M. L., ESCORCIO, E. The sambaquieira society from the perspective of sex and gender. R. Museu Arq. Etn., São Paulo, n. 21, p. 17-30, 2011.

\begin{abstract}
The research on sambaquis is a founding theme of Brazilian archaeology and there is a varied and extensive scientific production concerning this kind of archaeological site. Nevertheless, the great majority of the studies about the society that colonized the seashore aims to project on them some classification models that do not consider the different social segments that form them. The study of gender is a fruitful way to identify and characterize social segments that share the same space and ideology. Taking for background the path of the concept of gender in social sciences and its extensions to the archaeology of sambaquis this article analyses some elements of the mortuary contexts of these sites identifying the presence of symbolic constructions of extreme variability that point to some aspects of the social life among the fishercollectors of Rio de Janeiro State seashores.
\end{abstract}

Keywords: Sambaqui - Fishers-Collectors - Gender - Social Organization. 


\section{Referências bibliográficas}

ARNOLD, B.

2006 Gender and archaeological mortuary analysis. In: Nelson, S. M. (Ed.) Handbook of Gender in Archaeology. $2^{\text {nd }}$ Ed. Walnut Creek, Altamira Press: 137-170.

ARNOLD, J.E.

1996 The archaeology of complex hunter-gatherers. Journal of Archaeology Method and Theory, 3 (2): 77-126.

BARBOSA, M.

2007 A ocupação pré-colonial da Região dos Lagos, RJ: sistema de assentamento e relações intersocietais entre grupos sambaquianos e grupos ceramistas Tupinambá e da tradição Una. 356 f. 2v. Tese de Doutorado. Programa de Pós-Graduação em Arqueologia - Museu de Arqueologia e Etnologia, Universidade de São Paulo.

BEZERRA, F.O. da S.

1995 Sambaqui Arapuan, Guapimirim, RJ. In: Beltrão, M. (Org.). Arqueologia do Estado do Rio de Janeiro. Niterói: Arquivo Público Nacional.

BOURDIEU, P.

1992 A dominação masculina. Rio de Janeiro: Contra Capa.

BRUMBACH, H.J.; JARVENPA, R.

1997 Ethnoarchaeology of subsistence space and gender: a Subartic Dene case. American Antiquity, 62 (3): 414-436.

COLLIER, J.; YANAGISAKO, S.

1987 Gender and kinship. Essays toward a unified analysis. Stanford: Stanford University Press.

CONKEY, M.; SPECTOR, J.

1984 Archaeology and the study of gender. Advances in Archaeological Method and Theory, 7: 1-38.

DAHLBERG, F. (Ed.)

1981 Woman the gatherer. New Haven \& London: Yale University Press.

DE BLASIS, P.; FISH, K.; GASPAR, M.D.; FISH, P.R.

1998 Some references for the discussion of complexity among the sambaqui moundbuilders from the Southern shores of Brazil. Revista de Arqueologia Americana, 5: 75-105.

DE BLASIS, P.; GASPAR, M.D.; GIANNINI, P.; FIGUTI, L.; EGGERS, S.; SCHEEL-YBERT, R.; AFONSO, M.; FARIAS, D.; KNEIP, A.; MENDONÇA, C.; YBERT, J.

2004 Projeto Arqueológico do Camacho,
Processos formativos nos sambaquis do Camacho, SC: padrões funerários e atividades cotidianas. Relatório para FAPESP (98/8114-3).

DE BLASIS, P.; KNEIP, A.; SCHEEL-YBERT, R.; GIANNINI, P.C. e GASPAR, M.D.

2007 Sambaquis e Paisagem: dinâmica natural e arqueologia regional no litoral do Sul do Brasil. Arqueologia Suramericana, 3: 28-61

DURKHEIM, E.; MAUSS, M.

1971 [1903] De ciertas formas primitivas de clasificación. Contribuición al estudio de las representaciones colectivas. In: Mauss, M. Institución y Culto. Representaciones colectivas y diversidad de civilizaciones. Barcelona: Barral Editores.

ESCORCIO, E.; GASPAR, M.D.

2005 Indicadores de diferenciação social e de gênero dos pescadores-coletores que ocuparam a Região dos Lagos - RJ. Cadernos do LEPAARQ. Textos de Antropologia, Arqueologia e Etnologia, 3: 47-65.

ESCORCIO, E.M.

2008 Pescadores-coletores do litoral do estado do Rio de Janeiro: um olhar sobre idade e gênero. vii, 198 p. Dissertação de Mestrado. Programa de Pós-Graduação em Arqueologia - Museu Nacional, Universidade Federal do Rio de Janeiro.

ESCORCIO, E.; GASPAR, M.D.

2010 Um olhar sobre gênero: estudo de caso sambaquieiros do RJ. Revista de Arqueologia - SAB, 23 (1): 72-91.

ESTIOKO-GRIFFIN, A.; GRIFFIN, P.B.

1981 Woman the hunter: the Agta. In: Dahlberg, F. (Ed.) Woman the Gatherer. New Haven \& London: Yale University Press: 121-151.

FAUSTO, C.

2000 Os indios antes do Brasil. Rio de Janeiro: Jorge Zahar Editor.

FLANNAGAN, J. G.

1989 Hierarchy in simple "egalitarian" societies. Annual Review of Anthropology, 18: 245-266. Em: http://arjournals.annualreviews.org/ toc/anthro/18/1.

FRANCHETTO, B.; CAVALCANTI, M.L.V.C.; HEILBORN, M.L.

1981 Antropologia e Feminismo. In: Franchetto, B; Cavalcanti, M.L.V.C.; Heilborn, M.L. (Orgs.) Perspectivas antropológicas da 
mulher. v. 1. Rio de Janeiro, Zahar Editores: $11-47$.

GASPAR, M.D.

1991 Aspectos da organização social de um grupo de pescadores, coletores e caçadores: região compreendida entre a Ilha Grande e o delta do rio Paraíba do Sul, RJ. 374 f., 2v. Tese de Doutorado. Pós-Graduação em Antropologia Social, Área Interdepartamental em Arqueologia - Faculdade de Filosofia, Letras e Ciências Humanas da Universidade de São Paulo.

2004 ultura: Comunicação, Arte, Oralidade na Pré- História do Brasil. Revista do Museu de Arqueologia e Etnologia da Universidade de São Paulo, 14: 153-168.

GASPAR, M.D.; KLOKLER, D.M.; DE BLASIS, P.

(no prelo) Traditional fishing, mollusk gathering and the shellmound builders of Santa Catarina, Brazil, Journal of Ethnobiology.

HARAWAY, D.

1991 Simians, cyborgs and women. The reinvention of nature. New York: Routledge

HARRIS, O.; YOUNG, K. (Orgs.)

1979 Antropologia y Feminismo. Barcelona: Anagrama.

HÉRITIER, F.

1989 Masculino/Feminino. Enciclopédia Einaudi, vol. 20. Lisboa: Imprensa Nacional, Casa da Moeda.

JORDANOVA, L.

1980 Natural facts: a historical perspective on science and sexuality. In: McCormack, C.; Strathern, M. (Orgs.) Nature, Culture and Gender. Cambridge, Cambridge University Press: 42-69.

KLOKLER, D.M.

2008 Food for body and soul: mortuary ritual in shell mounds (Laguna - Brasil). PhD Thesis, Department of Anthropology, University of Arizona, Tucson.

2010 Comida para o corpo e alma: ritual funerário em sambaquis (Laguna - Brasil). Revista de Arqueologia, 23: 112 - 115.

KNEIP, A.

2004 O Povo da Lagoa: o uso do SIG para modelamento e simulação na área arqueológica do Camacho. Tese de Doutorado. Programa de Pós-Graduação em Arqueologia, Faculdade de Filosofia, Letras e Ciências Humanas, Universidade de São Paulo.

KNEIP, L.M.

1977 Pescadores e coletores pré-históricos do litoral de Cabo Frio, RJ. Coleção Museu Paulista. Sé- rie de Arqueologia, v.5. São Paulo: Fundo de Pesquisas da USP.

KNEIP, L.M. (Coord.)

1987 Coletores e pescadores préhistóricos de Guaratiba - Rio de Janeiro. Museu Nacional. Série Livros, V. Rio de Janeiro: Universidade Federal do Rio de Janeiro, Universidade Federal Fluminense.

KNEIP, L.M. (Org.)

2001 O sambaqui de Manitiba I e outros sambaquis de Saquarema, RJ. Documento de Trabalho no 5, Série Arqueologia. Rio de Janeiro: Departamento de Antropologia, Museu Nacional, Universidade Federal do Rio de Janeiro.

KNEIP, L.M.; MACHADO, L.C.

1993 Os ritos funerários das populações pré-históricas de Saquarema, RJ: sambaquis da Beirada, Moa e Pontinha. Documento de Trabalho $\mathrm{n}^{\circ}$ 1, Série Arqueologia. Rio de Janeiro: Departamento de Antropologia, Museu Nacional, Universidade Federal do Rio de Janeiro.

KNEIP, L.M.; MACHADO, L.C.; CRANCIO, F.

1995 Ossos humanos trabalhados e biologia esqueletal do sambaqui de Saquarema, RJ. Documento de Trabalho no 3, Série Arqueologia. Rio de Janeiro: Departamento de Antropologia, Museu Nacional, Universidade Federal do Rio de Janeiro.

LAQUEUR, T.

2001 Inventando o sexo: corpo e gênero dos gregos a Freud. Rio de Janeiro: Relume Dumará.

LEA, V.R.

1994 Gênero feminino Mebengôkre (Kayapó): desvelando representações desgastadas. Cadernos Pagu, 3: 85-115.

LEE, R.; DEVORE, I. (Eds.)

1968 Man the Hunter. New York: Aldine Publishing Company.

LÉVI-STRAUSS, C.

1976 Estruturas elementares do parentesco. Petrópolis: Editora Vozes. São Paulo: Editora da USP.

LIMA, T.A.

1991 Dos mariscos aos peixes: um estudo zooarqueológico de mudança de subsistência na pré-história do Rio de Janeiro. $691 \mathrm{f}$. 2v. Tese de Doutorado. Área Interdepartamental de Arqueologia da Faculdade de Filosofia, Letras e Ciências Humanas da Universidade de São Paulo.

2003 Estudos de gênero na arqueologia brasileira: por que não? Habitus, Goiânia v.1(1): 129-139. 
LIMA, T.A.; LOPEZ MAZZ, J.M.

1999 La emergencia de complejidad entre los cazadores recoletores de la costa atlántica meridional sudamericana. Revista de Arqueologia Americana, México, IPGH, 17, 18, y 19: $129-175$.

LIVRO DE TOMBO

Sítio Ilha da Boa Vista I, no 2118 a 2131.

MACHADO, L.C.

1984 Análise de remanescentes ósseos humanos do sítio Corondó, RJ. Aspectos biológicos e culturais. Tese de Doutorado. Departamento de Ciências Sociais da Faculdade de Filosofia, Letras e Ciências Humanas da Universidade de São Paulo. Rio de Janeiro: Instituto de Arqueologia Brasileira, Boletim - Série Monografias no 1 .

MACHADO, L.C.; PONS, E.; SILVA, L.

1989b Os sítios Massambaba (RJ-JC-56) e Boqueirão (RJ-JC-57), Arraial do Cabo. Os padrões de sepultamento. Dédalo, Publicação Avulsa I: 447-454.

MACHADO, L.C.; SENE, G.A.M.

2001 Simbolismo, identidade cultural e análise biológica: os remanescentes esqueletais humanos do sambaqui da Tarioba. In: Dias Jr., O.; Decco, J.; Froes, M.M. (Orgs.) A pré-história de Rio das Ostras. Sítio arqueológico sambaqui da Tarioba. Rio das Ostras: Fundação Rio das Ostras de Cultura, Inside: $51-87$.

MATHIEU, N.C.

1991 L'anatomie politique. Categorisations et ideologies $d u$ sexe. Paris: Côté femmes "Recherches".

MEAD, $\mathrm{M}$.

1969 Sexo e temperamento em três sociedades primitivas. São Paulo: Editorial Perspectiva.

MITHEN, S.

1996 A pré-história da mente. Uma busca das origens da arte, da religião e da ciência. São Paulo: Editora UNESP.

MOORE, H.

1994 A passion for difference. Bloomington: Indiana University Press.

NELSON, S.M.

2004 Gender in archaeology. Analyzing power and prestige. ( $2^{\text {nd }}$ ed.) Oxford: Altamira Press.

OKOMURA, M.; EGGERS, S.

2011 Grupos de afinidade no sambaqui Jabuticabeira II (SC): o que diz a morfologia craniana? Resumos do XVI Congresso Mundial da UISPP e Congresso da SAB, Setembro, Florianópolis.
ORTNER, S.; WHITEHEAD, H. (Eds.)

1981 Sexual meanings: the cultural construction of gender and sexuality. Cambridge: Cambridge University Press.

\section{OUDSHOORN, N.}

1994 Beyond the natural body. An archaeology of sex hormones. London \& New York: Routledge.

RAPPORT, N.; OVERING, J.

2000 Social and cultural anthropology. The key concepts. London: Routledge.

REITER, R. (Ed.)

1975 Toward an anthropology of women. New York: Monthly Review Press.

RODRIGUES-CARVALHO, C.

2004 Marcadores de estresse ocupacional em populações sambaquieiras do litoral fluminense. 183 f. Tese de Doutoramento. Fundação Instituto Oswaldo Cruz - Escola Nacional de Saúde Pública. Rio de Janeiro

RUBIN, G.

1975 The traffic in women: notes on the "political economy of sex". In: Reiter, R. (Ed.) Toward an anthropology of women. New York, Monthly Review Press: 157-211.

SCOTT, J.

1990 Gênero: uma categoria útil de análise histórica. Revista de Educação e Realidade. Porto Alegre, 15 (2): 5-22.

SENE, G.A.M.

2007 Indicadores de gênero na Pré-História brasileira: contexto funerário, simbolismo e diferenciação social. O sítio arqueológico Gruta do Gentio II, Unaí, Minas Gerais. xxiv, 389 p. Tese de Doutorado. Programa de Pós-Graduação em Arqueologia - Universidade de São Paulo. Museu de Arqueologia e Etnologia.

SHAPIRO, J.

1981 Anthropology and the study of gender. Soundings, an Interdisciplinary Journal, 64 (4): 446-465.

SILVA, M.

s/d www.antropologia.com.br/tribo/sextafei$\mathrm{ra} / \mathrm{pdf} /$ num2/masc_fem.pdf

STRATHERN, M.

1980 No nature, no culture: the Hagen case. In: McCormack, C.; Strathern, M. (Eds.) Nature, culture and gender. Cambridge: Cambridge University Press.

1988 The gender of the gift. Berkeley: The University of California Press. 
TABET, P.

1998 La construction sociale de l'inegálité des sexes: des outils et des corps. Paris: L'Harmattan. Bibliothèque du Feminisme.

TENÓRIO, M.C.

2003 O Lugar dos Aventureiros: identidade, dinâmica de ocupação e sistema de trocas no litoral do Rio de Janeiro há 3500 anos antes do presente. 644 p. 2 v. Tese de Doutorado. Programa de Pós-Graduação em História - Faculdade de Filosofia e Ciências Humanas, Pontifícia
Universidade Católica do Rio Grande do Sul. Porto Alegre.

UCHÔA, D.P.

1973 Arqueologia de Piaçaguera e Tenório: análise de dois sítios pré-cerâmicos do litoral paulista. 230 p. Tese de Doutorado. Faculdade de Filosofia, Ciências e Letras de Rio Claro.

VIVEIROS DE CASTRO, E.B.

2002 A inconstância da alma selvagem - e outros ensaios em antropologia. São Paulo: Cosac \& Naify.

Recebido para publicação em 30 de novembro de 2011. 